\title{
Estudo de caso de uma metodologia utilizada para a criação de uma coleção de moda
}

\section{Case study of a methodology used for the creation of a fashion collection}

\author{
Laiana Pereira da Silveira ${ }^{[1]}$, Frantieska Huszar Schneid ${ }^{[2]}$
}

\begin{abstract}
Resumo: $O$ artigo apresenta um estudo de caso que expõe ideias e traz exemplos de metodologias utilizadas para a criação e o desenvolvimento de uma coleção de moda, aplicadas ao longo do curso superior de tecnologia em Design de Moda do Instituto Federal Sul-rio-grandense campus Pelotas Visconde da Graça. As reflexões são apresentadas pelas autoras, uma delas docente do curso e outra egressa da primeira turma. Ao longo dos seis semestres de curso, foram criadas e desenvolvidas coleções de moda embasadas em Treptow (2013), que possui uma bibliografia atualizada e uma das mais completas na área de planejamento de coleção.
\end{abstract}

Palavras-chave: Metodologia. Design de Moda. Coleção de Moda. Planejamento de Coleção.

Abstract: The article presents a case study that presents ideas and brings examples of methodologies used for the development of a collection of fashion, requirements for higher education in technology. Fashion Design of the Federal Institute campus Sul-rio-grandense Pelotas Visconde da Graça. reflections are requested by the authors, one of the teachers of the course and another from the first class. The year of the course has been found to be the main series in Treptow (2013), which has a round bibliography and one round the phase of planning of collection.

Keywords: Methodology. Fashion design. Fashion Collection. Collection Planning.

[1] Graduação em Tecnologia em Design de

Moda, IFSUL.laianasilveira@gmail.com

[2] Doutorado (em andamento) em Memória Social e

Patrimônio Cultural, UFPEL. frantieskahs@gmail.com 


\section{INTRODUÇÃo}

O presente artigo tem como principal objetivo refletir sobre a metodologia utilizada para o planejamento e desenvolvimento de criação de uma coleção de moda, através de exemplos utilizados pelas autoras, uma como docente das disciplinas de Pesquisa de Moda, Desenvolvimento de Coleção I e II e Projeto Integrado Multidisciplinar de Moda II e III e a outra quando ainda era aluna do curso superior de tecnologia em Design de Moda do Instituto Federal Sul-rio-grandense campus Pelotas Visconde da Graça.

Visto que a aluna é egressa da primeira turma formada, e que ao longo destes três anos de formação houveram algumas alterações na matriz curricular do curso, será utilizada como base a matriz original, referente aos semestres 2015/1 e 2015/2, e a matriz atual, utilizada a partir do semestre 2016/1, ambas disponíveis no site da instituição.

De acordo com o projeto pedagógico atual do curso “através da disciplina de Projeto Integrado Multidisciplinar de Moda a Inter/transdisciplinaridade priorizando um modelo que integre diversas áreas do conhecimento e diversos níveis de ensino" (Projeto Pedagógico do Curso ${ }^{[3]}$ ). Através dessa disciplina, era possível integrar o conhecimento de todas as

[3] http://intranet.ifsul.edu. br/catalogo/curso/180 disciplinas já estudadas anteriormente com as do semestre atual desenvolvendo um único projeto.

No sexto e último semestre há a disciplina de Projeto Integrado Multidisciplinar $\vee$, referente ao sexto projeto desenvolvido pela autora, onde consta a reflexão sobre todo o conhecimento adquirido ao longo da graduação, e colocar em prática em um trabalho de conclusão de curso cuja finalidade foi o planejamento, o desenvolvimento e a criação de uma coleção de moda.

Para haver uma coerência nos projetos apresentados ao longo do curso e ter um norteador, foi adotada como metodologia principal para a área de criação de moda a metodologia desenvolvida por Treptow (2013), em que explica passo-a-passo todas as etapas produtivas de um planejamento de coleção. 
A metodologia a ser utilizada pode ser considerada algo muito pessoal, pois vai de cada professor e aluno identificar-se com os métodos de um autor. Segundo Prodanov (2013) "a metodologia é a aplicação de procedimentos e técnicas que devem ser observados para construção do conhecimento, com o propósito de comprovar sua validade e utilidade nos diversos âmbitos da sociedade" (PRODANOV, 2013, p. 14).

Lorgus e Odebrecht (2011) falam que em qualquer trabaIho de pesquisa é necessário deixar clara qual a opção de estrutura projetual que o pesquisador adota, explicar o porquê da opção de forma sucinta, mas jamais inequívoca. Nas palavras das autoras, os itens do passo-a-passo metodológico devem "ser relatados minuciosamente, conforme bem desenvolvidos, da mesma forma em que há preocupação em ser minucioso e preciso no capítulo metodológico. Estas providências garantem que o desenvolvimento do produto aconteça sobre bases sólidas e justificáveis". (LORGUS e ODEBRECHT, 2011, p. 56-57).

Esses procedimentos metodológicos servem para uma meIhor orientação no desenvolvimento do trabalho. Consequentemente, auxiliam na redução de erros ao desenvolver a pesquisa e otimizam o tempo do pesquisador. De acordo com Lilie (2013)

A elaboração de um produto necessita muito mais do que simplesmente uma ótima ideia. Se não há um caminho para se seguir, tende-se a andar em zigue-zague e perdese muito tempo corrigindo problemas que poderiam ter sido previstos, e até mesmo solucionados, muito antes de terem se tornado problemas de fato (LILIE, 2013, p.1).

Após escolher as metodologias a serem trabalhadas, começa então o desenvolvimento da pesquisa. Primeiramente, para que esse desenvolvimento seja executado, é preciso identificar a temática central, se ela foi estipulada ou se é livre. Partindo do atual estudo, a temática era livre, logo entra como uma das etapas metodológicas.

A primeira etapa é a escolha do tema e delimitação do tema para que possam ser desenvolvidas as futuras pesquisas criativas $^{[4]}$ e a etapa teórica[ ${ }^{[5]}$. Aqui serão mencionados

[4] Criação dos painéis de inspiração para o desenvolvimento da coleção.

[5] Etapa de revisão bibliográfica e aplicação de metodologias utilizadas para coleta de dados da pesquisa. 
os procedimentos apenas da etapa criativa. Logo abaixo, na figura 1, podem ser observados os itens solicitados para o desenvolvimento da etapa criativa.

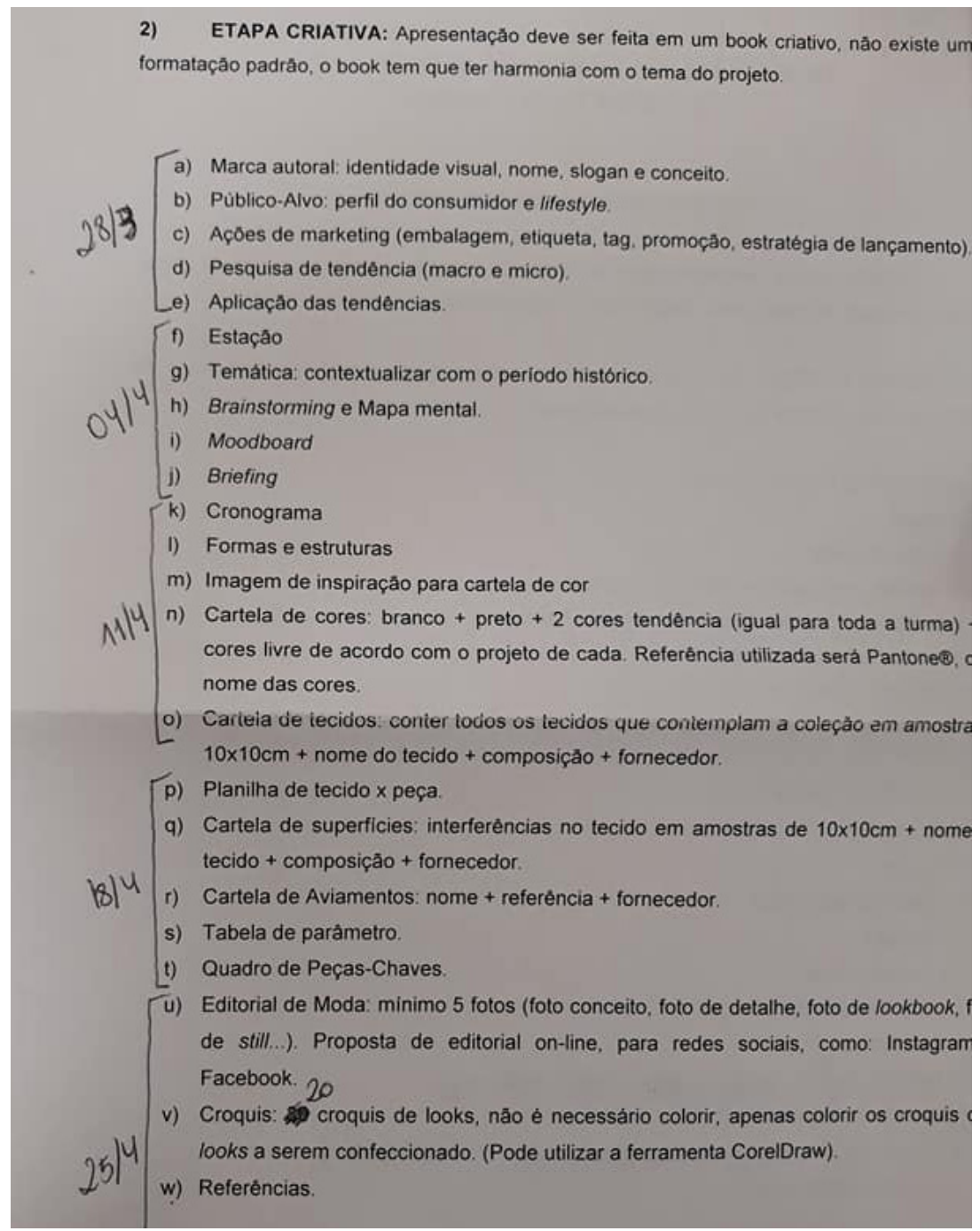

Figura 1: Passo-a-passo para o desenvolvimento de uma coleção de moda solicitados pela professora da disciplina. Fonte: Imagem elaborada pelas autoras.

Há algumas anotações de possíveis datas, sendo os primeiros esboços de cronograma de atividades. Para uma meIhor organização, foram criadas nove etapas a serem seguidas, de forma que auxiliasse numa melhor orientação para o planejamento e desenvolvimento da coleção. As etapas finais acabaram por mesclar-se com a etapa produtiva. Segue abaixo um quadro exemplificando as nove etapas. 
1 Escolha do tema e delimitação do tema. Seleção da marca que se deseja desenvolver a coleção de moda.

2 Cronograma da coleção, ao elaborar o cronograma o ideal é sempre ter um tempo extra, sabendo que poderá ocorrer algum tipo de imprevisto.

3 Planejamento, onde abrange a identificação de um problema, identificação do público-alvo e segmento.

4 Definições, como a estação a ser trabalhada e outros elementos da coleção.

$5 \quad$ Pesquisa de tendências e briefing.

6 Desenvolvimento das cartelas de cores e superfícies, escolha dos materiais a serem utilizados.

7 Parâmetro da coleção.

8 Realização da etapa produtiva.

9 Promoção do produto final.

Quadro 1 - Etapas do planejamento da coleção. Fonte: Desenvolvido pelas autoras

É possível identificar duas formas diferentes de organização do planejamento da coleção. A autora agrupou os itens e ordenou de forma que fosse facilitar no processo criativo, utilizando como base principal, os conceitos de Treptow (2013), que em alguns momentos complementa seus métodos apropriando-se de Seivewright (2007) e Pires (2000), outros dois autores da área.

A primeira etapa é composta pela escolha do tema e sua delimitação. Seus possíveis desmembramentos foram identificados por meio de um brainstorming (tempestade de ideias), método conhecido por propor soluções para as deficiências identificadas que de acordo com Baxter (2008) "brainstorming baseia-se no princípio: 'quanto mais ideias, melhor" (BAXTER, 2008, p. 68) e o mapa mental já contendo alguns direcionamentos para a coleção. E a seleção da marca que se deseja desenvolver a coleção de moda.

$\mathrm{Na}$ segunda etapa, foi desenvolvido o cronograma da coleção. De acordo com Treptow “a elaboração de um cronograma é a parte importante em qualquer projeto que se deseje realizar" (TREPTOW, 2013, p. 91), neste momento, definem-se 
as datas de cada etapa, e os prazos devem ser seguidos com muita responsabilidade, e ao elaborar o cronograma o ideal é sempre ter um tempo extra em cada fase, sabendo que poderá ocorrer algum tipo de imprevisto.

Na figura abaixo é possível analisar um exemplo utilizado para um projeto de coleção, em que é usado "meses" para orientação temporal e as atividades mais importantes selecionadas.

\section{CRONDGRAMA}

\begin{tabular}{c|c|c|c|c|c} 
ATIVIDADES & FEV & MAR & ABR & MAI & JUN \\
\hline PESQUISA DO TEMA & $\xi$ & & & & \\
PESQUISA DE INSPIRAÇÃo & $\xi$ & & & & \\
ETAPA TEÓRICA & & $\xi$ & & & \\
BOOK CRIATIVO & & & $\xi$ & $\xi$ & \\
CROQUIS & & & & $\xi$ & \\
EDITORIAL DE MODA & & & & & $\xi$ \\
VITRINA & & & & & $\xi$ \\
ENTREGA & & & & & $\xi$
\end{tabular}

Figura 2 - Cronograma de atividades. Fonte: Desenvolvido pelas autoras.

A terceira etapa é quando se inicia o planejamento da coleção, onde abrange a identificação de um problema, que neste caso seria a criação de uma coleção de moda feminina que faça com que o público-alvo da marca escolhida deseje o produto. Compreender os critérios de avaliação deste problema e gerar soluções através das pesquisas realizadas, bem como, com a marca já selecionada, identificar o público-alvo e lifestyle e criar um moodboard (painel de inspiração). 
Pesquisa de público-alvo e lifestyle, além de acompanhar os hábitos de consumo do seu público e os interesses atuais, Seivewright (2007) fala que "o designer deve acompanhar o espírito da época (zeitgeist) para perceber mudanças no gosto e interesse dos consumidores" (apud TREPTOW, 2013, p. 73). Agora também é de grande valia ouvir o consumidor, o feedback é tão importante quanto saber dos gostos pessoais. Sayeg e Dix (2015) falam do principal fator que determina o comportamento do consumidor:

A cultura é o principal fator que determina nosso comportamento de compra. No Brasil, os aspectos culturais na moda são a valorização do corpo, a informalidade de relacionamento, a alegria manifestada nas músicas, roupas e palavreado, a hipervalorização de ídolos, principalmente do futebol (Pelé, "Ronaldos", Neymar Jr.) e da TV (Xuxa, Faustão, Silvio Santos, entre outros), a preferencia por cores tropicais e, ultimamente por causa de acontecimentos políticos, a crescente aceitação aos processos que julgam e ameaçam a impunidade histórica de empresários e políticos da cena brasileira. (SAYEG e DIX, 2015, p. 57)

Escolher a segmentação de mercado que deseja ser trabalhada, Treptow diz que "os critérios de segmentação podem ser geográficos, demográficos, psicográficos ou comportamentais" (TREPTOW, 2013, p. 48), é neste momento que os painéis imagéticos auxiliam a identificar o consumidor através de suas preferências e poder aquisitivo, está diretamente ligado às pesquisas anteriores.

Os painéis desenvolvidos podem possuir diversos formatos e informações, desde modelos digitais, quanto a painéis feitos de forma manual, quanto mais livre for essa etapa criativa, mais rica em elementos que futuramente possam contribuir e serem usados na criação da coleção.

$\mathrm{Na}$ quarta etapa temos as definições de alguns elementos da coleção, escolhendo assim a estação a ser trabalhada, os materiais a serem utilizados nos looks, definir o período histórico contextualizando com a temática, as formas e estruturas, a imagem de inspiração e cartela de cores. 
A quinta etapa é quando se dá início as pesquisas e montagens de painéis. A primeira pesquisa desenvolvida é a de tendência, que se divide em macro e micro, no caso das micro tendências, para Treptow, "são importantes para visualizar os elementos de estilo em evidência" (TREPTOW, 2013 p. 102), após divulgadas as pesquisas, sabe-se quais os desejos e anseios do consumidor, seleciona-se o que é desejável usar na coleção, quais cores são apostas e quais já estão saturadas, qual o design e a silhueta deve-se investir, para poder criar um produto que o consumidor enxergue e associe a novidade. "Compreender as tendências significa penetrar os mecanismos de imitação, de difusão dos gostos, e o papel de indicador social que eles podem desempenhar" (ERNER, 2015, p. 10).

A pesquisa de micro tendências é feita em cima dos principais desfiles de moda do mundo, como Milan Fashion Week, Paris Fashion Week, São Paulo Fashion Week, Londres Fashion Week e New York Fashion Week, seleciona-se elementos que apareceram repetidamente e que podem agregar a coleção. É possível analisar na figura abaixo um exemplo de painel de micro tendências.

\section{PESQUISA DE TENDÊNCIAS // MICRD}

Transparência, mix de texturas, brilho, assimetria, estrutura, silhueta um pouco mais marcada, fendas e volumes.
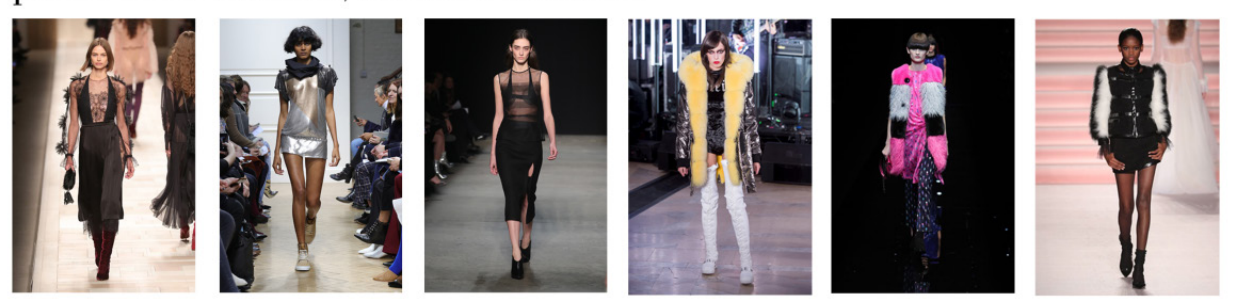

\section{FENDI}

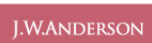

NARCISO RODRIGUEZ PHILIPP PLEIN
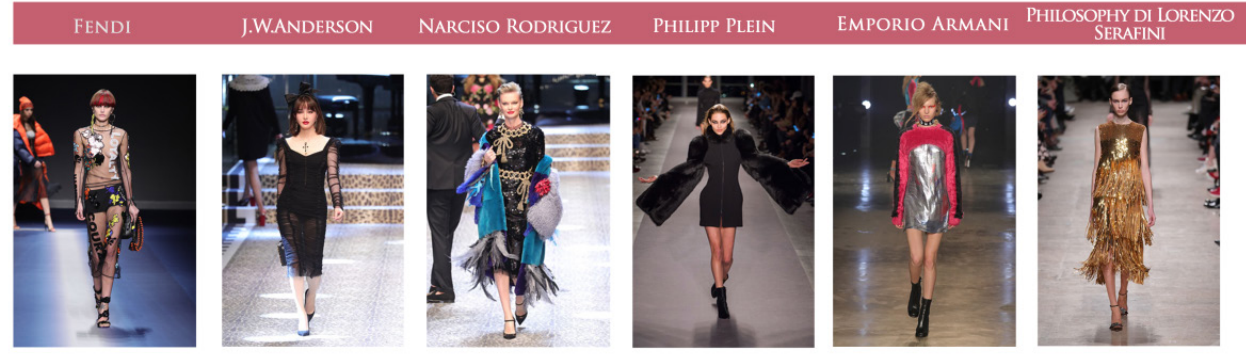

VERSACE

DOLCE \& GABbANA DOLCE \& GABBANA BRANDON MAXWELL

VERSUS

ROCHAS

Figura 3 - Painel de micro tendências. Fonte: Desenvolvido pelas autoras. 
As macro tendências são um pouco mais complexas, são grandes movimentos ou fluxos socioculturais, que influenciam a sociedade, e também são influenciadas pela mesma, a cultura, o consumo, por períodos de tempo mais longos, para a moda nada mais é do que a observação do comportamento em geral do consumidor, a frequência de compra, a análise do produto adquirido, se o interesse foi na tendência adquirida, na quantidade de peças ou na qualidade, se ele passa mais tempo fazendo compras, conhecendo culturas diferentes, ou com a família.

Após todas as etapas anteriores concluídas, cria-se o briefing da coleção, um texto técnico informativo, Seivewright (2007) resume "o briefing tem o propósito de inspirar o designer e listar os objetivos a serem alcançados com a coleção, ao mesmo tempo em que delimita as condições para sua execução" (apud TREPTOW, 2013, p. 100), é o texto onde constam informações como: cores, tecidos, formas e silhuetas, inspiração da coleção, quantidade de peças e quais peças, a estação, tendências, público-alvo, estilo.

Essa sexta etapa ocorre à escolha dos materiais utilizados na coleção, cores e superfícies previamente selecionados, são criadas as cartelas definitivas. Para a criação de cartela de cores, foi estipulado o número de oito cores referentes à temática, sendo elas duas cores tendência, branco, preto e quatro cores livre. Para facilitar na escolha das cores, é possível escolher uma imagem de inspiração que sirva como auxiliadora na escolha das cores.

Para o desenvolvimento da cartela e uma melhor visualização, foram selecionados alguns padrões a serem seguidos, como o de utilizar os códigos de cores da Pantone e de acordo com Treptow (2013), o ideal é que as amostras possuam 2 $\mathrm{cm} \times 3 \mathrm{~cm}$ com intervalo de $1 \mathrm{~cm}$ entre elas, e fundo branco.

Para a criação das demais cartelas, de tecidos, superfícies e aviamentos, não é estipulado um número mínimo de amostras, mas o ideal para as duas primeiras, é de manter um padrão nas amostras, obedecendo a um tamanho mínimo de $10 \mathrm{~cm} \times 10 \mathrm{~cm}$, possuir identificação com nome, composição 


\section{CARTELA DE CORES}

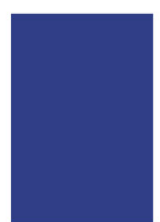

19-3952 TPX Surf the Web

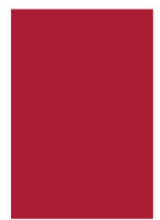

18-1657 TPX Salsa

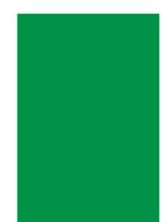

17-6153 TPX Fern Green

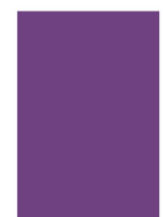

19-3536 TPX Amaranth Purple

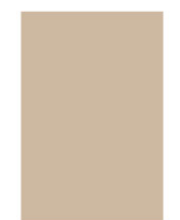

13-1012 TPX Frosted Almond

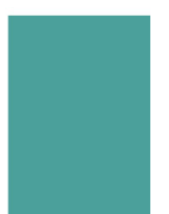

16-5418 TPX Lagoun

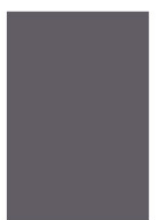

18-3905 TPX

Excalibur

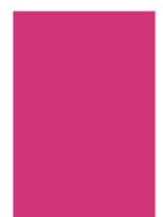

18-2140 TPX Cabaret

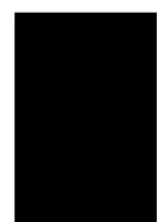

Preto

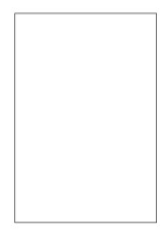

Branco
Figura 4 - Cartela de cores Fonte: Desenvolvido pelas autoras

e fornecedor, e se possível usar algum tipo de acabamento para que os tecidos não desfiem. E a cartela de aviamentos deve possuir as mesmas identificações exigidas nos tecidos.

A sétima etapa é quando se estipula o parâmetro da coleção, momento em que é definido o tamanho da coleção, através do mix de produtos ${ }^{[6]}$, sabe-se a quantidade exata das peças a serem confeccionadas, para auxiliar na escolha de materiais, pode-se criar uma tabela com o cruzamento de mix de produtos e cartela de tecidos, identificando quantas vezes o mesmo tecido será utilizado e em quais peças. Como parâmetro da coleção, cria-se uma tabela com o cruzamento do mix de moda e o mix de produtos. É definida através do mix de moda a classificação de cada peça, existem três ca-

[6] "A empresa de moda não pode viver de um único produto. O GPM - gerente de produto de moda - deve ter a consciência de que é imprescindível um conjunto de itens para sustentar as vendas necessárias à manutenção da atividade empresarial e distribuição de lucros ao seu proprietário" (SAYEG e DIX, 2015, p. 97). tegorias utilizadas, são elas: fashion, vanguarda e básico. De acordo com Pires (2000):

Básicos: modelos que estão presentes em quase todas as coleções. Peças funcionais que costumam ter venda garantida. Fashion: modelos que estão comprometidos com as tendências do momento através de formas, cores e padronagem. Modelos que devem ser comercializados durante o período da coleção, pois, no futuro, não estarão mais em moda e não representarão atrativo para o consumidor. Vanguarda: são peças complementares. 
Comprometidas com as tendências atuais ou futuras, nem sempre apresentam características muito comerciais. São as peças "mais diferentes" que carregarão o "espírito da coleção" e poderão ser usadas em vitrines, fotos e desfiles, pois são peças de impacto maior, que chamam a atenção do consumidor, ainda que este opte por um produto mais simples ou mais em conta (apud TREPTOW, 2013, p. 96).

Na oitava etapa, começa o processo de realização da coleção, quando é colocado em prática todas as pesquisas e informações que arrecadamos ao longo do processo teórico e criativo. Junto com a tabela de parâmetros, começa a fase de criação das peças da coleção com os esboços, que são os primeiros desenhos das possíveis peças da coleção. Frings (2012, p. 230) fala que: "No papel, o designer pode ver em duas dimensões quais elementos de design melhor complementam um ao outro. Ele também deve ser capaz de imaginar como a peça ficará em três dimensões, quando feita em um tecido."

Sem se preocupar com a apresentação do desenho, é importante pensar na versatilidade da peça, e exercitar a criatividade desenhando para aprimorar as ideias. Escolhidas as peças, confere-se com a tabela de parâmetros para ver se não há necessidades de alterações, faz-se agora os croquis finais da coleção, que podem ser feitos a mão ou computadorizado, neste caso serão feitos a mão e anexados ao book criativo. Na figura abaixo, pode-se observar três looks que compuseram a coleção.

Com os looks definidos, dá-se início a elaboração das peças, considerando alguma tabela de medidas femininas padrão para toda a coleção. Junto à modelagem de cada peça, deve ser criada uma ficha técnica. Esta ficha é "o documento descritivo de um modelo de coleção. Esse documento contém, em detalhes, a discriminação de uma peça de moda. Pode-se dizer que a ficha técnica é o mapeamento do DNA de cada produto" (SAYEG e DIX, 2015, p. 105). Não existe uma regra sobre as informações que devem conter, mas algumas informações consideradas importantes são: nome da empresa ou marca, referência, segmento, graduação, estação, coleção, designer, modelista, 

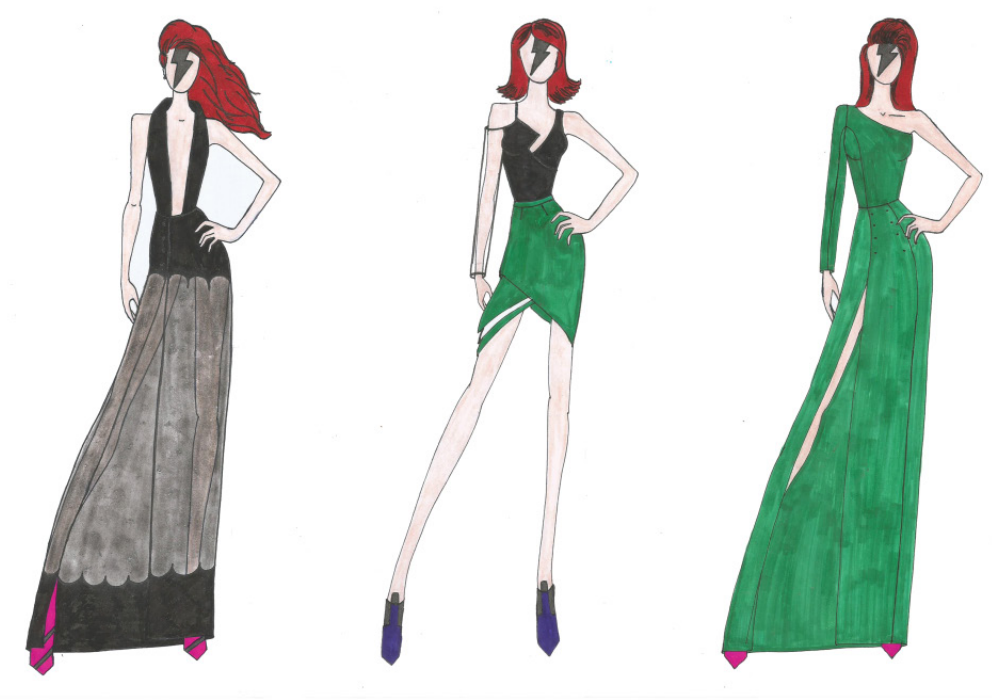

Figura 5 - Parte da coleção Fonte: Desenvolvido pelas autoras.

pilotista, data de criação, desenho técnico, croqui, descrição da peça, descrição de insumos (informações sobre o tecido junto de amostra e informações sobre aviamentos junto de amostra), sequência operacional, fluxograma e componentes.

E por último, a nona etapa, que é a promociona[[7], esta etapa do projeto serve para a divulgação do produto final, existem alguns que podem variar de acordo com o poder de investimento da marca/loja/empresa, Treptow (2013) cita alguns meios de divulgação como a participação em feiras nacionais e internacionais, releases da coleção divulgado em veículos de comunicação, desfiles e editoriais de moda para catálogos.

Para este estudo de caso específico, foi realizada a promoção do produto através de um editorial de moda, onde é preciso definir a locação que será ambientada as fotos, escolha da modelo, escolha do fotógrafo, cabelo, maquiagem, acessórios para compor os looks, fatores climáticos e elementos para compor a cena, na figura abaixo estão algumas das fotos do editorial.

De acordo com a temática que era Glam Rock, e o look confeccionado ser conceitual, ou seja, o mais ousado da coleção, que serve de inspiração para as demais peças comerciais. É possível notar que, optou-se por valorizar na produção dos elementos para compor o look, comoa bota de glitter prateado e nos demais acessórios, do que nos elementos de cenário.
[7] "Promoção de vendas, também conhecida como marketing direto, é usada para aumentar a demanda e incrementar as vendas de produtos e serviços específicos e tem por objetivo tornar a marca e suas mercadorias ou serviços mais atraentes para os clientes, oferecendo incentivos adicionais para a compra ou um prêmio". (POSNER, 2015, p. 184). 


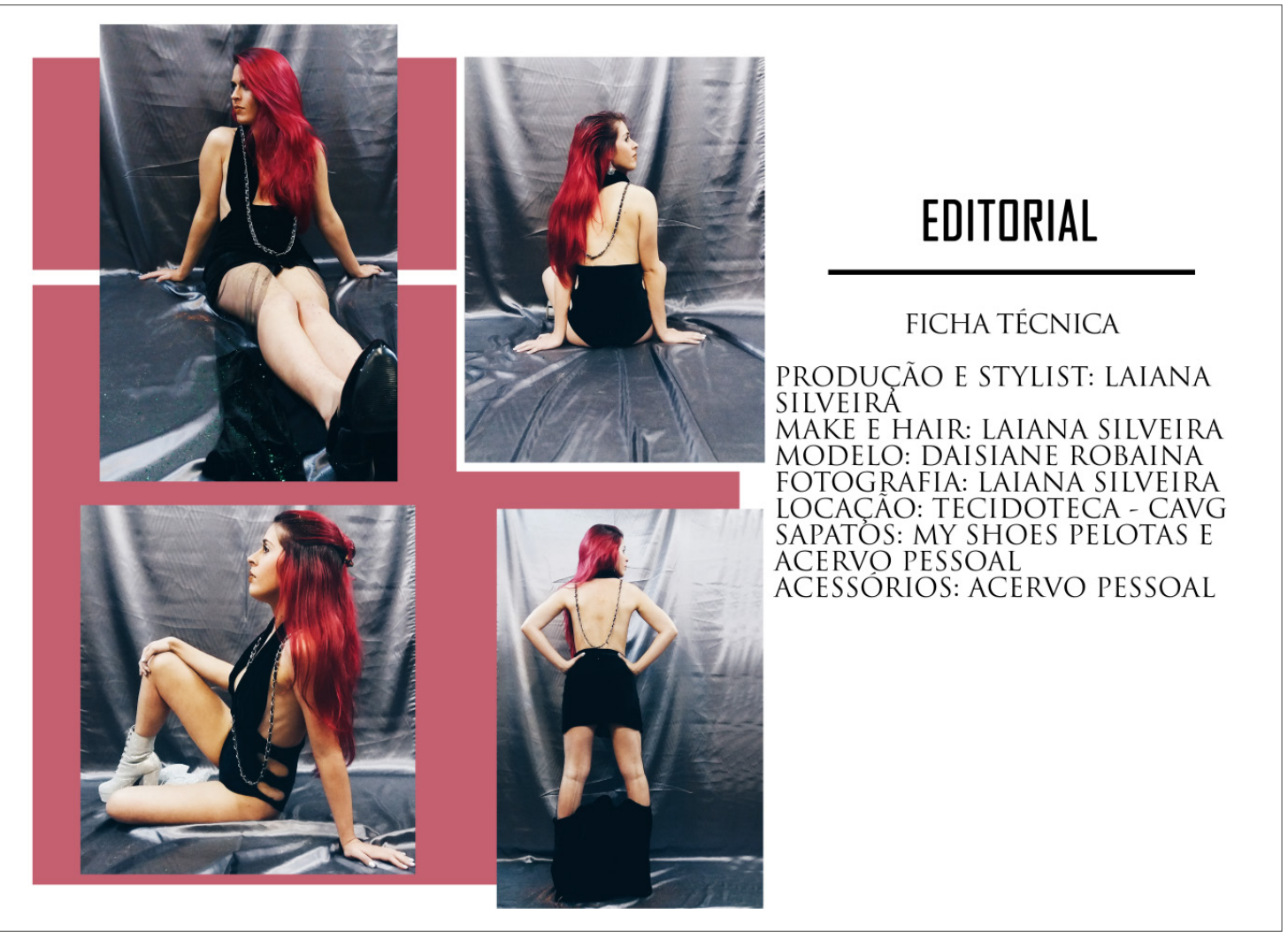

\section{CONSIDERAÇÕES FINAIS}

O objetivo principal deste artigo foi de apresentar uma metodologia para o desenvolvimento de um produto de moda, através da aplicação em um estudo de caso específico. Os procedimentos metodológicos apresentados foram adaptados baseados em conceitos existentes de autores do design e da moda.

É possível visualizar que, ao escolher uma metodologia que o pesquisador identifique-se e sinta-se a vontade de utilizar, serve como um facilitador na estruturação da pesquisa. Nesse estudo de caso, por exemplo, é visível que não há uma necessidade de utilizar a metodologia de um único autor de forma engessada, e sim que, é admissível moldá-la de forma que seja eficaz.

Tanto quando são citados alguns conceitos utilizados por Treptow (2013), é possível notar que a própria autora se apropria de outros autores para criar sua própria metodologia. Isso demonstra como mesclar métodos, e como essa adaptação pode funcionar de uma forma prática para o pesquisador.
Figura 6 - Editorial de moda produzido para a coleção Fonte: Desenvolvido pelas autoras. 


\section{REFERÊNCIAS BIBLIOGRÁFICAS}

BAXTER, Mike. Projeto de produto: Guia prático para o design de novos produtos. São Paulo: Edgard Blucher, 2008.

ERNER, Guillaume. Sociologia das tendências

/ Guillaume Erner; tradução Julia da Rosa

Simões. -1ed. - São Paulo: Gustavo Gili, 2015.

FRINGS, Gini Stephens. Moda: do conceito ao consumidor / Gini Stephens Frings; tradução: Mariana Belloli; revisão técnica: Eloize Navalon, Luiz Carlos Robinson. - 9ed. - Porto Alegre: Bookman, 2012.

INSTITUTO FEDERAL SUL-RIO-GRANDENSE CAMPUS PELOTAS VISCONDE DA GRAÇA. Curso superior de tecnologia em design de moda. Disponível em: http://intranet.ifsul. edu.br/catalogo/curso/180 Acesso em: 06 mai 2019.

LILIE, Larissa. Mapa Fashion: uma proposta de desenvolvimento de coleção. Disponível em: http:// www.coloquiomoda.com.br/anais/Coloquio\%20de\%20 Moda\%20-\%202013/POSTER/EIXO-1-DESIGN_POSTER/ Mapa-Fashion-uma-proposta-de-desenvolvimentode-colecao.pdf Acesso em: 06 mai 2019.

LORGUS, Alexandra Luiza. Metodologia de pesquisa aplicada ao design / Alexandra Luiza Lorgus, Clarisse Odebrecht, Blumenau: Edifurb, 2011.

POSNER, Harriet. Marketing de moda / Harriet Posner ; [traducao Márcia Longaraço]. - São Paulo: Gustavo Gili, 2015.

SAYEG, Carla Marcondes. Gerência de produtos

de moda / Carla Marcondes Sayeg e Luis Tadeu Dix. São Paulo: Estação das Letras e Cores; Rio de Janeiro: Ed. Senac Rio de Janeiro, 2015.

TREPTOW, Doris. Inventando moda: planejamento de coleção. - 5. Ed. São Paulo: Edição da Autora, 2013. 